\title{
Upper Lateral Incisor Replacement With Socket Preservation and An Implant After A Failed Resin-Retained Bridge (RRB): A Case Report and Literature Review
}

\author{
Barry K Ramcharan and Reisha N Rafeek* \\ University of the West Indies, Trinidad \& Tobago
}

Submission: November 15, 2018; Published: December 05, 2018

*Corresponding author: Dr Reisha Rafeek, Faculty of Medical Sciences, School of Dentistry, University of the West Indies, Trinidad \& Tobago

Abstract

Introduction: Several options exist for practitioners to replace an upper lateral incisor such as a denture, conventional bridge, resin-retained bridge or an implant. Patients have to make choices based on finances and other considerations and the options vary in terms of long term success rates.

Case Report: This report focused on a patient with a failed resin retained bridge where socket preservation technique with freeze-dried bone aggregate (FDBA) and collagen membrane was performed and subsequently five months later an implant was placed to replace the missing upper lateral. The implant was osseo-integrated for nine months before the patient returned to have the abutment and temporary crown placed. The patient remained with the temporary crown for over ten months before returning for treatment.

Conclusion: Well-designed treatment plans can benefit practitioners and patients to avoid undesirable consequences with failed restorative options. Advanced surgical and restorative techniques must be carefully planned and the need for teamed collaboration between restorative specialists and general dental practitioners be considered. The report shows the more ideal and predictable option of socket preservation prior to implant placement for replacing an upper lateral incisor.

Keywords: Socket preservation; Implant; Bridge

\section{Introduction}

The case of a missing incisor in patients due to history of trauma, congenital absence and non-optimal hygiene is common ranging from childhood to adulthood [1,2]. Despite the causes, treating space closure has largely remained similar and unchanged for three (3) decades; a single tooth removable prosthesis, a fixed bridge, (either fixed-fixed design or cantilever winged prosthesis, conventional preparation or resin retained), or with titanium dental implants assisting with rehabilitation of similar anterior sites.

As expected, not all sites are the same as patients are either forced to conform to one of the three treatment options mentioned above. Factors to include are costs [3], hard and soft tissue site condition due to patient history, aesthetics, occlusal function and timing amongst others. Systematic reviews indicate that the five-year survival rates for resin-retained bridgework is $87.7 \%$, conventional bridgework over $90 \%$ and an implant retained single crown $94.5 \%$ [4]. With respect to resin-retained bridges, although survival rates may be high, complications like de-bonding are frequent [5].
The use of socket preservation, as a precursor stage of treatment to ultimately include implants as the final definitive treatment may be considered a fourth addition to traditional treatment options offered to patient at first consultation. Following extraction, recent literature has documented horizontal bone loss of $29 \%$ to $63 \%$ and vertical bone decreases of $11 \%$ to $22 \%$ after 6 months [6]. The physiologic benefits of alveolar ridge preservation are well documented in the literature [7]. Preservation of extraction sockets (either infected or not) and augmentation of post extraction sockets, positioned early in the management of edentulous sites with $>5 \mathrm{~mm}$ bony defects, may be a useful tool utilized by clinicians early in the decision process when determining treatment options with patients.

Implants placed into socket-grafted sites performed as well as those placed into non-grafted sites [8]. Araujo et al. [9], also demonstrated that placing a biomaterial into the extraction socket enhances bone remodeling and compensates for marginal ridge resorption. Different socket preservation techniques have been widely used in controlled and uncontrolled studies with different materials and systems; bone grafting alone including autografts, 


\section{Advances in Dentistry \& Oral Health}

xenografts, allografts and alloplasts, membrane alone (resorbable or not) and bone grafts with a membrane [10]. A graft integration period (about 3-9 months) with use of a transitional denture or transitional winged Maryland type bridge as in the case being described to rehabilitate edentulous sites over a prolonged treatment period to maintain optimal functionality and aesthetics may be best suited to certain patients.

\section{Case Report}

A fifty-four (54) year old male of mixed ethnicity, in good medical health with no known allergies, presented with pain in his upper right lateral incisor in April 2015. History revealed trauma secondary to motor vehicular accident. The patient was examined, and a periapical radiograph revealed periradicular periodontitis with severe vertical and horizontal bone loss with the patient being advised to extract the tooth. The patient was also advised on short-term tooth replacement treatment options with either an immediate upper denture or a resin-retained bridge and long term care with titanium dental implant. The tooth was subsequently extracted immediately with metronidazole $400 \mathrm{mg}$ bid and an over the counter (OTC) non-steroidal anti-inflammatory drug (NSAID) prescribed for a week. At the one-week review, $5 \mathrm{~mm}$ gingival pockets were charted around upper central incisor. The patient opted for a resin-retained (Maryland) bridge option, non-desirous of a removable prosthesis.

In May 2015 a resin-retained bridge preparation was completed with minimal palatal reduction, extending from the upper right central incisor and upper right canine with suitable guide planes but no incisal reduction. The occlusion was checked and cleared of interferences and an upper polyvinyl siloxane (PVS) impression (Defend Super Hydrophilic VPS light body and putty impression material, Mydent, IL, USA) taken and sent to the laboratory with shade selection along with a lower opposing study model and fabrication instruction prescribing for a Resin retained bridge (RRB). Two weeks later the RRB was returned, tried in and cemented with a dual cure adhesive resin luting cement (Rely X Ultimate, 3M ESPE, Irvine, CA, USA). The patient was satisfied with both fit and aesthetics of the bridge.

Three (3) months later in August 2015 the bridge de bonded at the metal cement interface of the central incisor but retained in situ. The RRB was re- cemented with Rely X dual cure luting cement after the metal fitted bonding surfaces were piezo electric ultrasonically scrubbed with a stainless steel attachment (Beyes Dental Canada Inc, Scarborough, ON, Canada).

However, only one and a half months later, the bridge de cemented again and this time was re cemented with glass ionomer luting cement (Glassline glass ionomer cement, PULPDENT Watertown, MA, USA) upon cleaned and etched bonding surfaces. The bridge stayed seated for another 6 months before de bonding for a $3^{\text {rd }}$ time within one year. The bridge was then re bonded with Panavia (Kuraray America Inc, New York, NY, USA) and wing perforations were incorporated with the attempt to enhance surface area and mechanical lock bonding. At this stage the patient was referred to the first author (BKR) for implant placement.
In April 2016 it was decided that bone grafting was necessary prior to implant placement so bone particulate (size $0.25-1.0 \mathrm{~mm}$ ) (mineralized freeze-dried bone aggregate, FDBA) (Osteolife Biomedical, Miami, FL, USA) and an H shaped 20 by 20 collagen membrane graft (Osteolife Biomedical, Miami FL, USA) were placed over upper right lateral incisor position to a depth of $13 \mathrm{~mm}$ and gingival tissues manipulated for primary closure as an "uninfected socket preservation technique". A buccal mucoperiosteal full thickness three sided flap was raised using mesial and distal relieving incisions with number 15 blade and periosteal elevator blunt dissection. The graft site was identified into which fissure burr slow speed on low torque setting used to debride alveolar and lamina dura bone with soft tissue and callous removal under copious irrigation. The particulate aggregate was incrementally introduced and packed into the debrided clotted blood pooled site to the targeted, desired vertical bone height (Figure 1). The resorbable membrane was measured and trimmed to the defect dimensions and carefully overlaid onto alveolar ridge with emphasis to tuck sheet margins beyond flap incision lines both labially and palatally for stability, as well as to occlude the newly grafted socket (Figure 2a). Resorbable, loosely tacked 3/0 vicryl sutures were placed achieving hemostasis and primary surgical site closure.

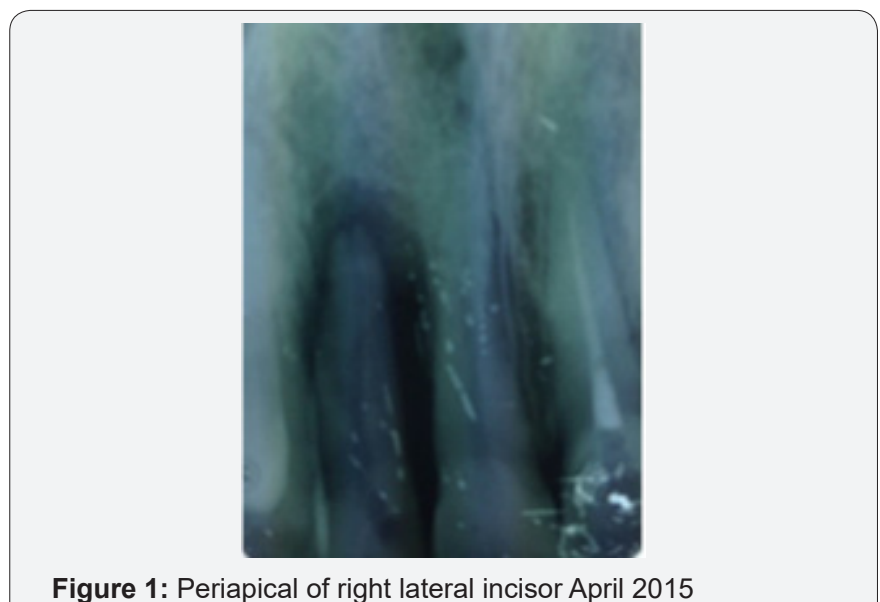

Figure 1: Periapical of right lateral incisor April 2015

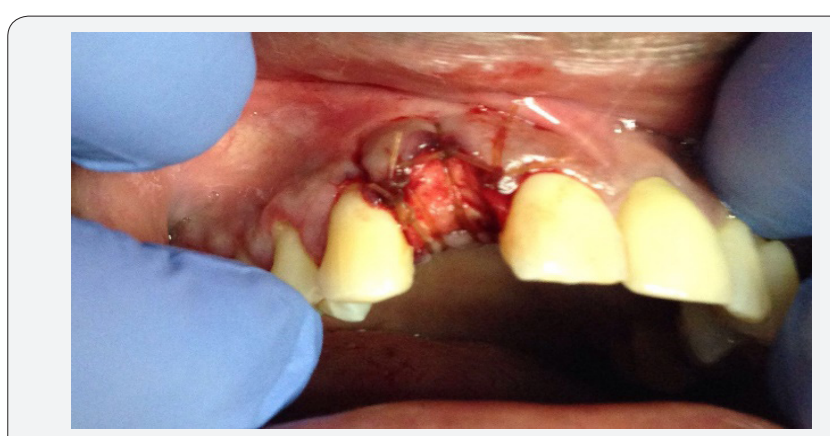

Figure 2a: Bone particulate and graft membrane placed prior to implant April 2016

The RRB was reattached with glass ionomer luting cement after relief adjustments to the pontic gingival porcelain surface (Figure 2b). The patient was then reviewed one week (Figure 2c) and one month (Figure 2d) respectively thereafter for healing 


\section{Advances in Dentistry \& Oral Health}

assessment. The patient was reviewed once monthly to assess graft integration.

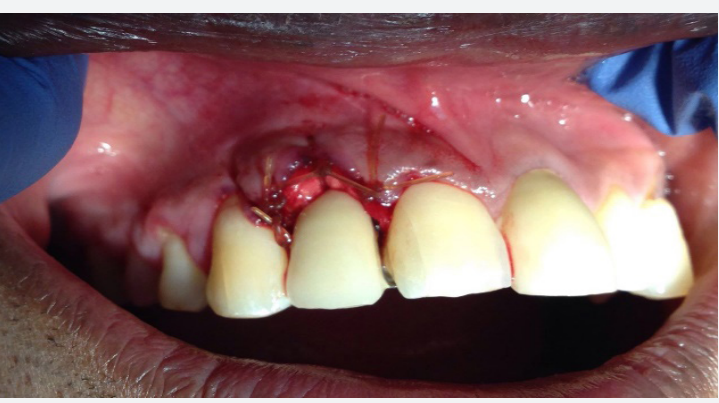

Figure 2b: RRB recemented after graft placement April 2016

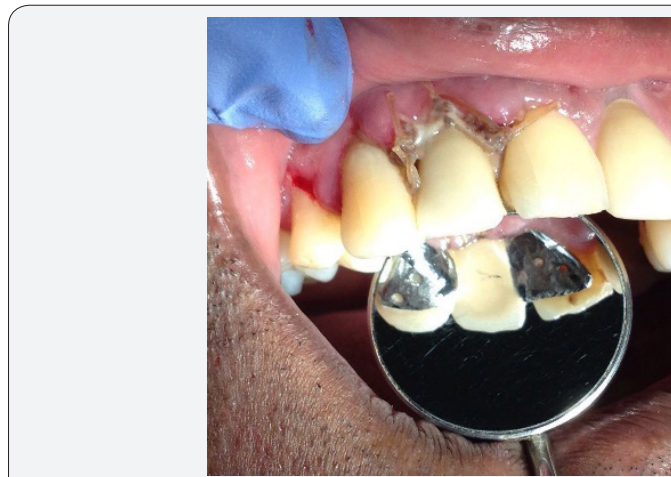

Figure 2c: One week review April 2016.

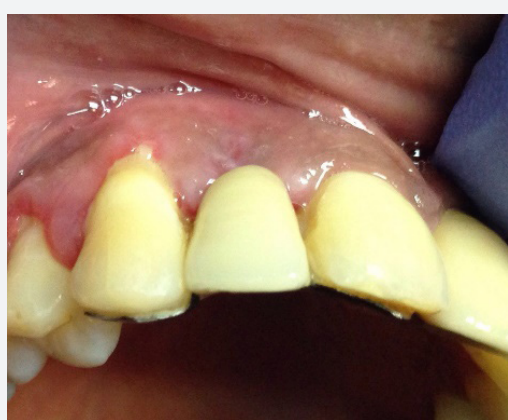

Figure 2d: One month review after graft May 2016

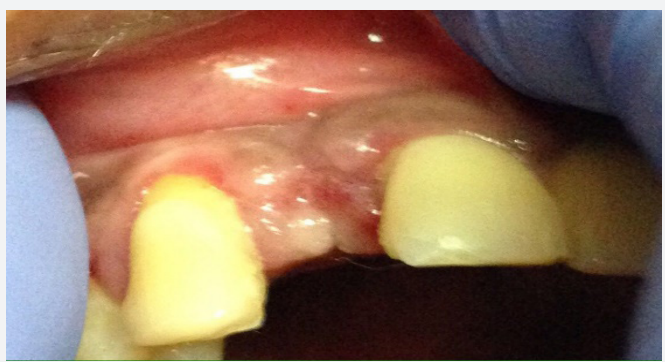

Figure 3a: 5 months after graft September 2016.

The implant surgery was then performed five (5) months later in September 2016. The stages are shown pre-operatively (Figures $3 a$ ), then initial drill hole (Figure $3 \mathrm{~b}$ ), guide pin placement (Figure 3c) and implant fixture (Figure 3d). A periapical radiograph taken (Figure 4) that shows implant placement at approximately $13 \mathrm{~mm}$ using Biomorse internal hex 4.0 diameter $13.0 \mathrm{~mm}$ long implant from Bionnovation (Bionnovation Biomedical Bauru, SP, Brazil).

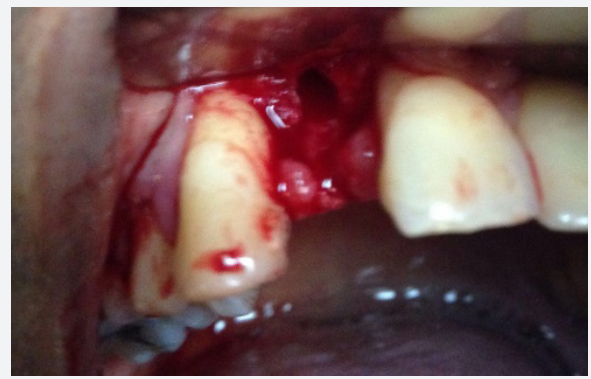

Figure 3b: Implant placement: Initial drill hole.

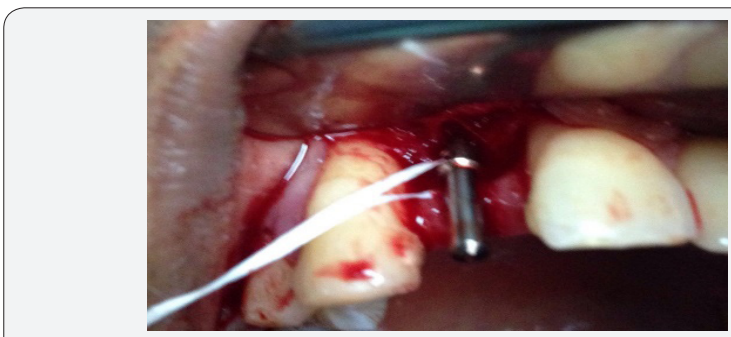

Figure 3c: Guide pin placement.

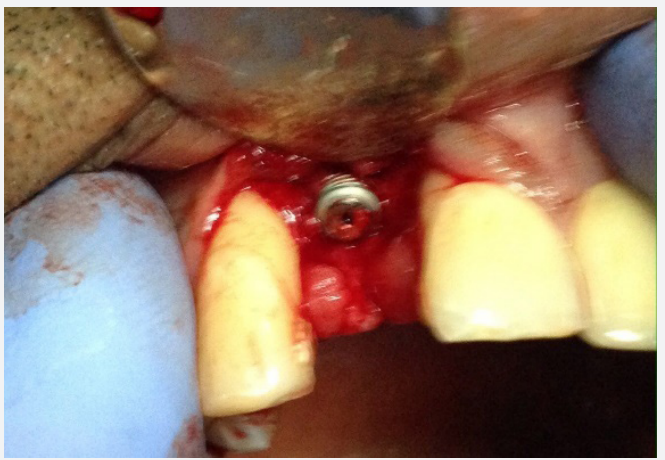

Figure 3d: implant fixture.

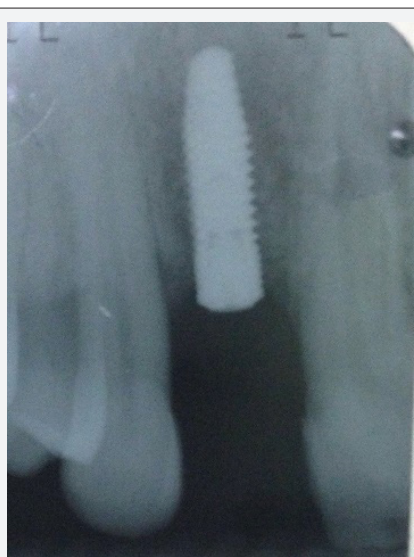

Figure 4: Periapical of implant placement September 2016.

The patient was then left for 9 months with periodic review visits to assess continued osseointegration of implant and graft integration. Figure 5a is a periapical radiograph which shows implant after 9 months with the RRB cemented still in place and Figure $5 \mathrm{~b}$ shows the clinical view. A putty stent heavy body polyvinyl siloxane (VP Mix Putty, Henry Schein, New York, USA) of the anterior teeth was made (Figure $5 \mathrm{c}$ ) in order to fabricate a temporary crown. The RRB was then removed (Figure 6a), then the 


\section{Advances in Dentistry \& Oral Health}

healing screw was exposed (Figure 6b) via a second stage surgery performed with gingival tissue full thickness subperiosteal flap with mesial and distal relieving incisions introduced to advance the flap to allow for suturing. The cover screw was removed (Figure 6c) and the abutment placed (Figure 6d). The abutment was then torqued with rotational force of $30 \mathrm{Ncm}$ pressure (Figure 7a) and the flap was folded upon itself to create a better emergence profile after 4.5 by 1.5 by $6.0 \mathrm{~mm}$ straight abutment placement and then sutured (Figures $7 \mathrm{~b} \& 7 \mathrm{c}$ ). The temporary crown was then fabricated using a polysiloxane stent of the RRB and temporary crown material (Protemp, 3M ESPE, St Paul, MN, USA) as seen in the labial and palatal views (Figure 8a). Final anterior view of patient with temporary crown (Figure 8b).
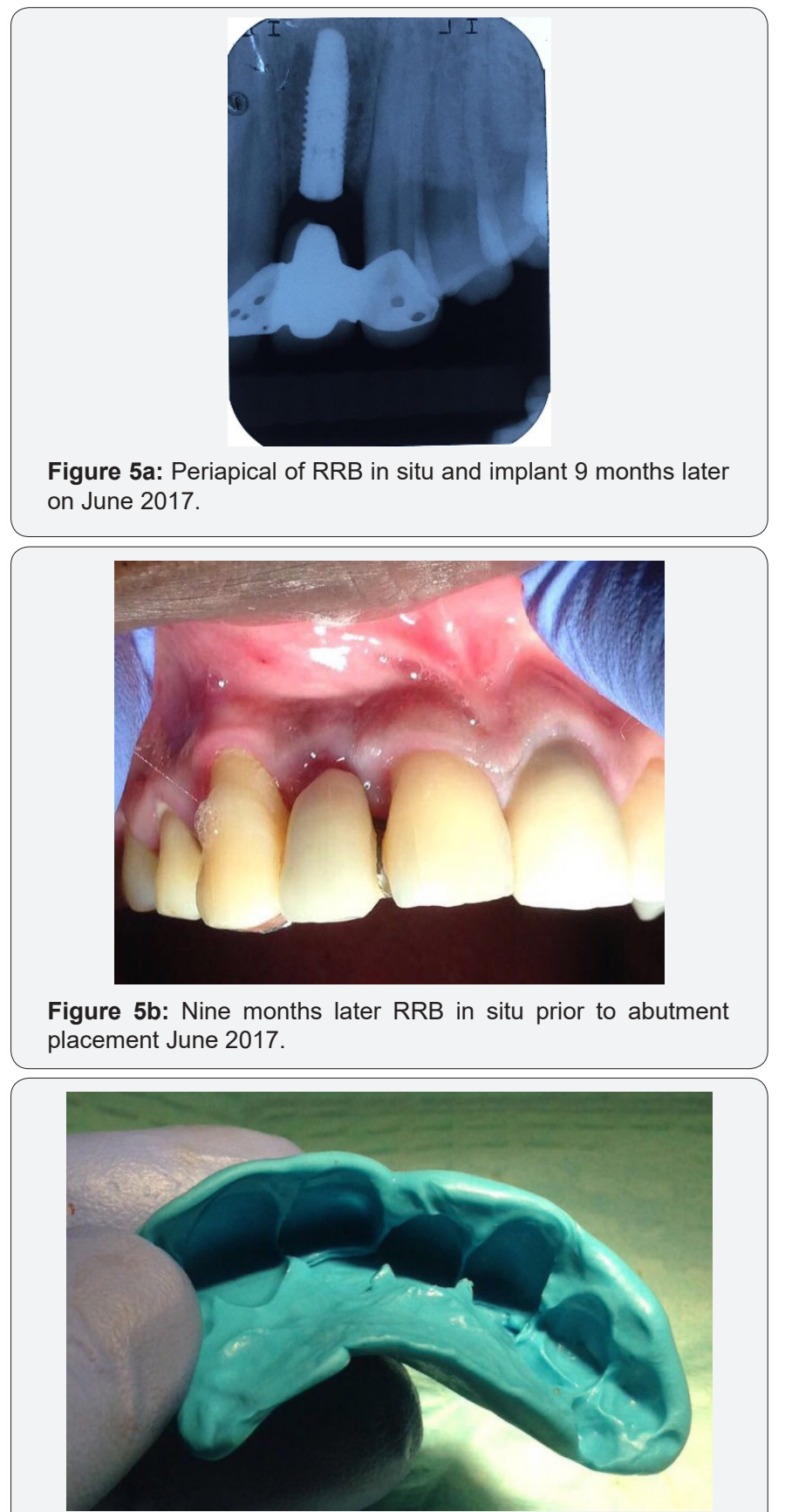

Figure 5c: Putty stent as a matrix for temporary.

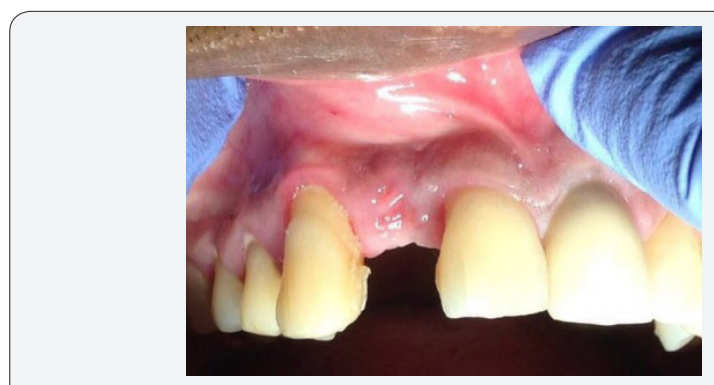

Figure 6a: RRB removed.

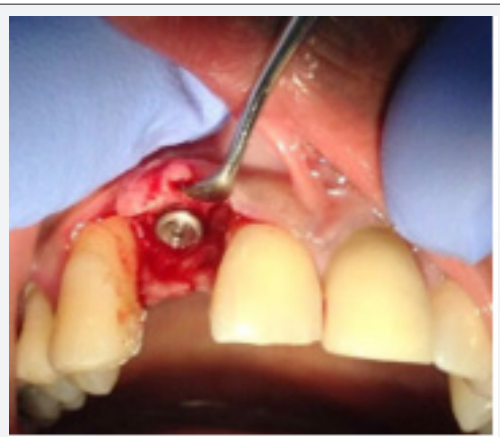

Figure 6b: Implant exposed.

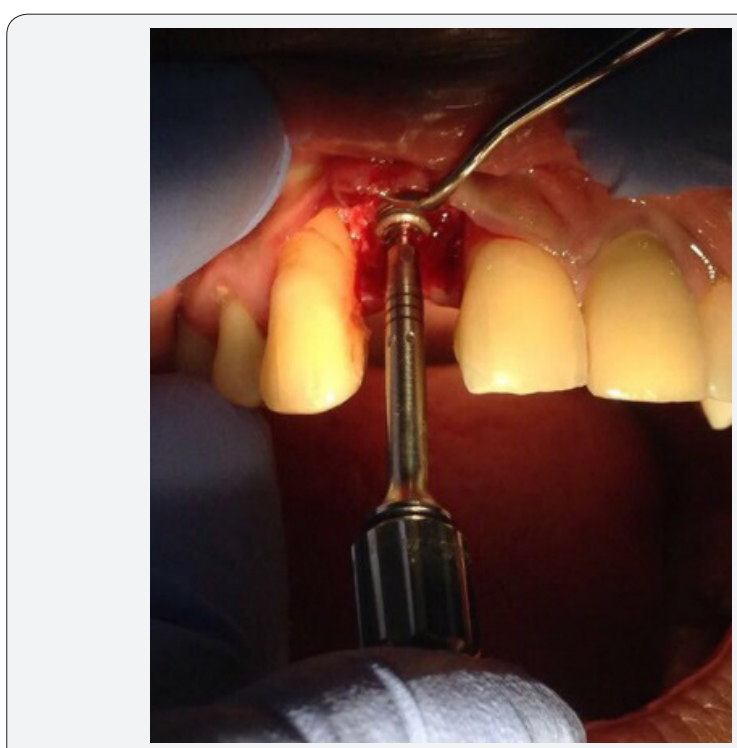

Figure 6c: Cover screw removal.

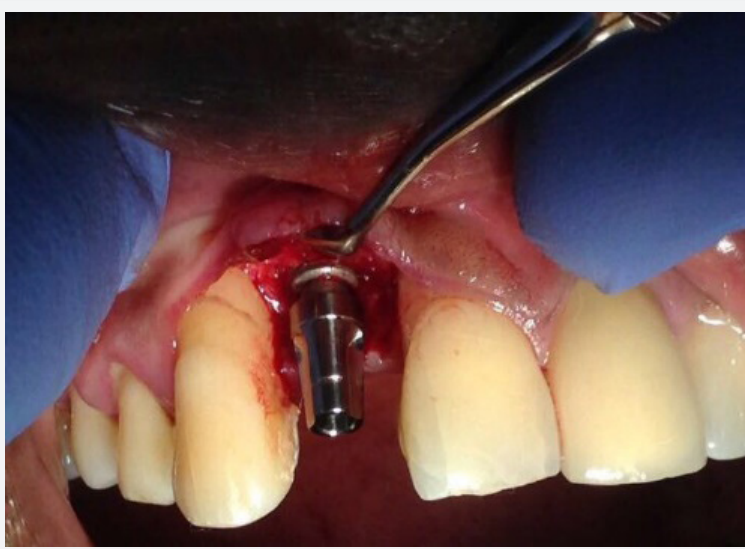

Figure 6d: Abutment placed. 


\section{Advances in Dentistry \& Oral Health}

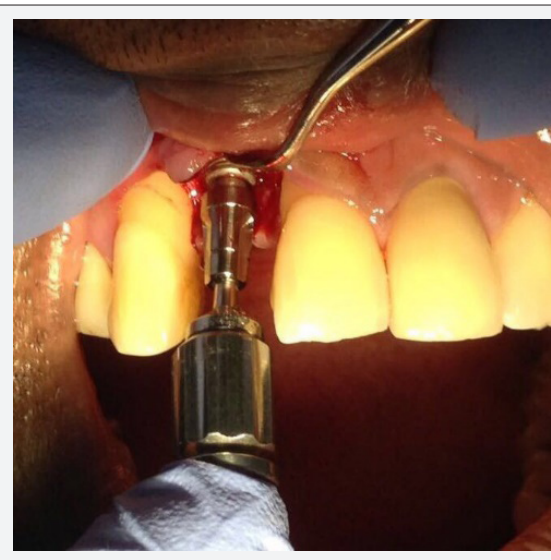

Figure 7a: Abutment torque.

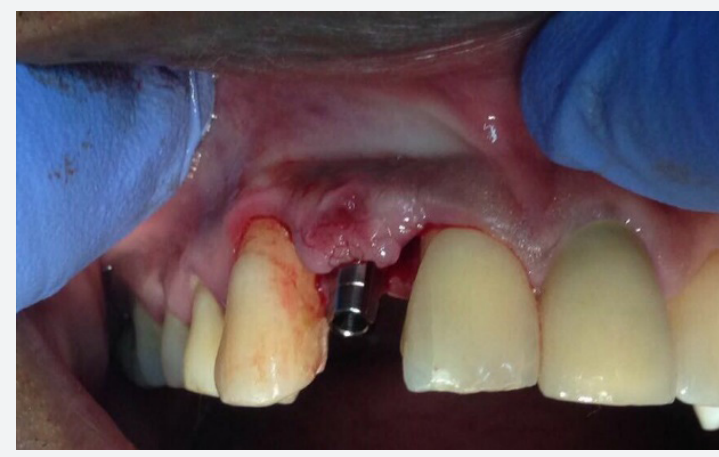

Figure $7 \mathbf{b}$ : Abutment with soft tissue.

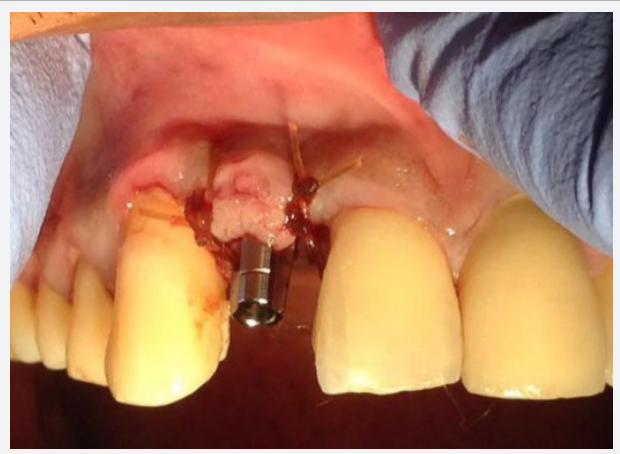

Figure 7c: Abutment with soft tissue sutured.

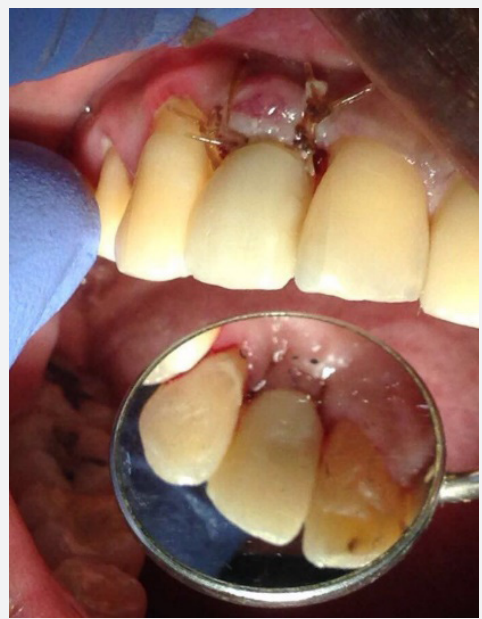

Figure 8a: Temporary crown on abutment: palatal view and labial views.

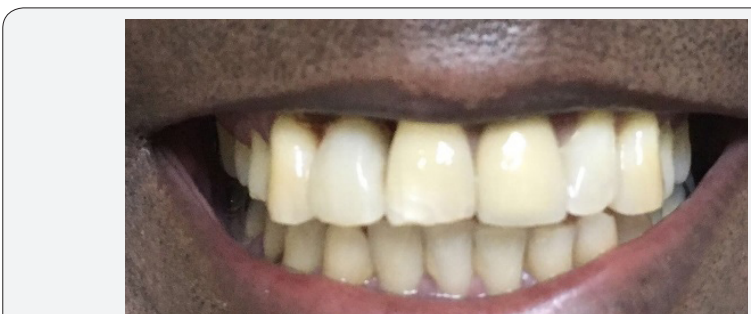

Figure 8b: Anterior view of upper lateral temporary crown June 2017.



Figure 8c: Final crown on upper right lateral 6 months post op October 2018.

Patient then returned 10 months later in April 2018 with the temporary crown still intact and tissues healed and said he was happy with his temporary crown hence the delay in definitive treatment. He then had the final crown placed and has been very pleased up to the six months follow up (Figure 8c).

\section{Discussion}

The survival rates for resin retained bridges are lower than for implants [4] but patients may have to opt for the RRB due to financial constraints. They may also choose the fixed RRB option over the removable denture for a transitional provisional before implants as in this case. With respect to RRBs and its design, best outcomes show that cantilevers survive better than fixed-fixed RRB $[11,12]$ and anterior survive better than posterior [13]. The restoration design and operator skill also positively influence the RRB success [14]. The reasons for failure are wringing forces $[11,15]$, the resin layer of cement [16], initial occlusion [17] and the retainer- prosthesis design [18]. Re-bond failure rates are high [19]. In this case report, the initial RRB debonded after 3 months and was probably due to the lack of coverage on the palatal surfaces plus the fixed-fixed design debonding due to differential tooth movement. A cantilever design may have been more successful.

The extraction of a tooth results in the socket healing from apex towards the crest $[6,20]$. This bone loss reduces the possibility of implant placement later on and so simple socket preservation of the extraction site should become a routine procedure following extraction of teeth [21]. The benefits of socket preservation have been documented [7] however there are many different techniques used [10] but no consensus has been reached on the ideal protocol [22]. In this case report, an uninfected socket preservation technique was used where a flap was raised, the 


\section{Advances in Dentistry \& Oral Health}

socket prepared with a slow speed burr to debride the socket and encourage bleeding and then packed with FDBA and covered with a collagen membrane graft [23].

Implant surgery was performed 5 months after the graft and the patient returned after 9 months of osseointegration of the implant before the abutment and temporary crown were placed. The patient was happy with the temporary and did not seek definitive treatment until 10 months later.

\section{Conclusion}

Well-designed treatment plans can benefit practitioners and patients to avoid undesirable consequences with failed restorative options. Advanced surgical and restorative techniques must be carefully planned and the need for teamed collaboration between restorative specialists and general dental practitioners be considered. The report shows the more ideal and predictable option of socket preservation prior to implant placement for replacing an upper lateral incisor.

\section{References}

1. al-Wahadni A, Linden GJ, Hussey DL (1999) Periodontal response to cantilevered and fixed-fixed resin bonded bridges. Eur J Prosthodont Restor Dent 7(2): 57-60.

2. Romberg E, Wood M, Thompson VP, Morrison GV, Suzuki JB (1995) 10 -year periodontal response to resin bonded bridges. J Periodontol 66(11): 973-977.

3. Creugers NH, Käyser AF (1992) A method to compare cost-effectiveness of dental treatments: adhesive bridges compared to conventional bridges. Community Dent Oral Epidemiol 20(5): 280-283.

4. Durey KA, Nixon PJ, Robinson S, Chan MF (2011) Resin bonded bridges: techniques for success. Brit Dent J 211(3): 113-118.

5. Pjetursson BE, Tan WC, Tan K, Bragger U, Zwahlen M, et al. (2008) A systematic review of the survival and complication rates of resinbonded bridges after an observation period of at least 5 years. Clin Oral Implants Res 19(2): 131-141.

6. Tan WL, Wong TL, Wong MC, Lang NP (2012) A systematic review of post-extractional alveolar hard and soft tissue dimensional changes in humans. Clin Oral Implants Res.;23(suppl 5):1-21.

7. Avila-Ortiz G, Elangovan S, Kramer KW, Blanchette D, Dawson DV (2014) Effect of alveolar ridge preservation after tooth extraction: a systematic review and meta-analysis. J Dent Res 93(10): 950-958.

8. Barone A, Orlando B, Cingano L Marconcini S, Derchi G, et al. (2012) A randomized clinical trial to evaluate and compare implants placed in augmented versus non-augmented extraction sockets: 3-year results. ] Periodontol 83(7):836-846.

9. Araújo MG, Lindhe J (2009) Ridge alterations following tooth extraction with and without flap elevation: an experimental study in the dog. Clin Oral Implants Res 20(6): 545-549.

10. Orgeas GV, Clemntini M, de Risi V, de Sanctis M (2013) Surgical techniques for alveolar socket preservation: A systematic review. Int J of Oral \& Maxillo Implants 28(4): 1049-1061.

11.van Dalen A, Feilzer AJ (2003) [Cantilever resin-bonded bridges with one adhesive surface. A review of the literature]. Ned Tijdschr Tandheelkd 110(4): 143-148.

12. Hussey DL, Pagni C, Linden GJ (1991) Performance of 400 adhesive bridges in a restorative dentistry department. J Dent 19(4): 221-225.

13. Creugers NH, De Kanter RJ, van't Hof MA (1997) Long-term survival data from a clinical trial on resin-bonded bridges. J Dent 25(3-4): 239242.

14. King PA, Foster LV, Yates RJ, Newcombe RG, Garrett MJ (2015) Survival characteristics of 771 resin-retained bridges provided at a UK dental teaching hospital. Br Dent J 218(7): 423-428.

15. Ziada HM, Orr JF, Bennington IC (2000) Photoelastic stress analysis in perforated (Rochette) resin bonded bridge design. J Oral Rehabil 27(5): 387-393.

16. Berekally TL, Makinson OF, Pietrobon RA (1993) A microscopic examination of bond surfaces in failed electrolytically etched cast metal fixed prostheses. Aust Dent J 38(3): 229-235.

17. Creugers NH, Snoek PA, van 't Hof MA, Käyser AF (1989) Clinical performance of resin-bonded bridges: a 5-year prospective study. II. The influence of patient-dependent variables. J Oral Rehabil 16(6): 521-527.

18. Bhakta S, van Noort R, Cardew G (2006) Improved retention of anterior cantilever resin-bonded prostheses by design alteration: an experimental and finite element study. J Prosthet Dent 95(3): 209-217.

19. Creugers NH, van't Hof MA, Schmänk VM (1990) [Reinserting loosened bonded bridges]. Dtsch Zahnarztl Z 45(10):625-628.

20. Kosinski T (2016) A simple and cost effective socket preservation technique. Cont Educ 35(4): 90.

21. American Dental Association (2007). 2005-2006 Survey of Dental Services Rendered. American Dental Association Chicago IL, USA.

22. Horowitz R, Holtzclaw D, Rosen PS (2012) A review on alveolar ridge preservation following tooth extraction. J Evid Based Dent Pract 12(suppl 3): 149-160.

23. Garg A, Ayangco L Practical soft tissue management for dental implants and natural teeth. Chapter $11,1^{\text {st }}$ Edition Garg Multimedia Group Inc. Miami, FL, USA.

\section{Your next submission with Juniper Publishers will reach you the below assets}

- Quality Editorial service

- Swift Peer Review

- Reprints availability

- E-prints Service

- Manuscript Podcast for convenient understanding

- Global attainment for your research

- Manuscript accessibility in different formats ( Pdf, E-pub, Full Text, Audio)

- Unceasing customer service

Track the below URL for one-step submission https://juniperpublishers.com/online-submission.php 